This item was submitted to Loughborough's Research Repository by the author.

Items in Figshare are protected by copyright, with all rights reserved, unless otherwise indicated.

\title{
The role of tributary relative timing and sequencing in controlling large floods
}

PLEASE CITE THE PUBLISHED VERSION

http://dx.doi.org/10.1002/2013WR014067

\section{PUBLISHER}

(c) American Geophysical Union

\section{VERSION}

VoR (Version of Record)

\section{LICENCE}

CC BY-NC-ND 4.0

\section{REPOSITORY RECORD}

Pattison, lan, Stuart N. Lane, Richard J. Hardy, and Sim M. Reaney. 2019. "The Role of Tributary Relative Timing and Sequencing in Controlling Large Floods". figshare. https://hdl.handle.net/2134/16660. 


\title{
QAGUPUBLICATIONS
}

\section{Water Resources Research}

\section{RESEARCH ARTICLE \\ 10.1002/2013WR014067 \\ The role of tributary relative timing and sequencing in controlling large floods}

Key Points:

- Tributary timing is a significant control on downstream flooding

- Synergy occurs between two

subwatersheds, meaning impacts are unpredictable

- Modifying biophysical properties play an important management due to timing

Correspondence to:

I. Pattison,

i.pattison@lboro.ac.uk

Citation:

Pattison, I., S. N. Lane, R. J. Hardy, and

S. M. Reaney (2014), The role of

tributary relative timing and

sequencing in controlling large floods,

Water Resour. Res., 50, 5444-5458,

doi:10.1002/2013WR014067.

Received 3 MAY 2013

Accepted 1 JUN 2014

Accepted article online 6 JUN 2014

Published online 7 JUL 2014

\author{
lan Pattison', Stuart N. Lane2, Richard J. Hardy³, and Sim M. Reaney ${ }^{3}$ \\ ${ }^{1}$ School of Civil and Building Engineering, Loughborough University, Loughborough, Leicestershire, UK, ${ }^{2}$ Faculte des \\ geosciences et de l'environnement, Universite de Lausanne, Lausanne, Switzerland, ${ }^{3}$ Department of Geography, Durham \\ University, Durham, UK
}

\begin{abstract}
Hydrograph convolution is a product of tributary inputs from across the watershed. The timespace distribution of precipitation, the biophysical processes that control the conversion of precipitation to runoff and channel flow conveyance processes, are heterogeneous and different areas respond to rainfall in different ways. We take a subwatershed approach to this and account for tributary flow magnitude, relative timing, and sequencing. We hypothesize that as the scale of the watershed increases so we may start to see systematic differences in subwatershed hydrological response. We test this hypothesis for a large flood (T> 100 years) in a large watershed in northern England. We undertake a sensitivity analysis of the effects of changing subwatershed hydrological response using a hydraulic model. Delaying upstream tributary peak flow timing to make them asynchronous from downstream subwatersheds reduced flood magnitude. However, significant hydrograph adjustment in any one subwatershed was needed for meaningful reductions in stage downstream, although smaller adjustments in multiple tributaries resulted in comparable impacts. For larger hydrograph adjustments, the effect of changing the timing of two tributaries together was lower than the effect of changing each one separately. For smaller adjustments synergy between two subwatersheds meant the effect of changing them together could be greater than the sum of the parts. Thus, this work shows that while the effects of modifying biophysical catchment properties diminishes with scale due to dilution effects, their impact on relative timing of tributaries may, if applied in the right locations, be an important element of flood management.
\end{abstract}

\section{Introduction}

It is generally argued that the magnitude and frequency of river flooding is increasing throughout the world [Douglas et al., 2000; Robson, 2002; Hannaford and Marsh, 2007; Petrow and Merz, 2009; Cunderlik and Ouarda, 2009; Delgado et al., 2010], and that possible climate changes [Huntington, 2006] may exacerbate this trend. While attempting to slow the rate of climate change associated with human impacts has been identified as a necessary mitigation measure, it is increasingly recognized that adaptation to possible future hydrological extremes will be required [Quevauviller, 2011]. Such adaptation can include reducing exposure and vulnerability to river flood events. But, it may also include adaptation of the biophysical properties of watersheds, more colloquially known as "land management" as a means of reducing flood magnitude and hence flood risk. The reduction is delivered through changes in the attenuation of river flow, so as to reduce the peak flow in geographically delimited areas of concern during a significant flood event. Attenuation is thought to be augmented (see summary in Lane et al. [2007]) through changes in water balance at the watershed scale (e.g., increases in evapotranspiration losses), changes in the timing of delivery of runoff from hillslopes (e.g., slowing the rate of runoff) or increases in temporary or permanent storage within rivers and floodplains (e.g., through encouraging flood inundation in areas where flooding might serve ecosystem benefits, such as wetlands). Management of biophysical properties in this way may be linked to ideas regarding ecosystem restoration [Maltby and Acreman, 2011] under the assumption that in less degraded landscapes (e.g., natural woodland cover; more tightly coupled river-floodplain systems; undrained wetlands), flow attenuation is naturally greater.

This paper is concerned with a commonly overlooked element of the management of biophysical properties in river flood management: the question of scale. Scale has been well recognized as a critical variable in governing watershed hydrological response. Notably, Blöschl et al. [2007] contrasted climate and land use 
a)

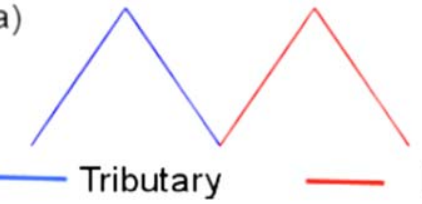

b)

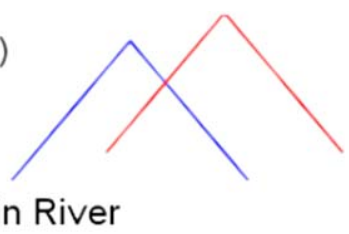

Figure 1. Effect of tributary synchronicity with respect to the main river on downstream peak flow magnitudes.

change impacts upon high river flows. They argued that, except for the very largest watersheds, climatic changes are likely to impact entire watersheds. However, land use changes are likely to be more local in impact, with the magnitude of this impact decreasing with increasing scale.

It follows that there is a critical spatial scale at which land use change impacts switch from being detectable to being undetectable. Identification of this switch is important in identifying those spatial scales at which management of biophysical watershed properties remains a viable option for reducing flood magnitude and hence flood risk.

A critical control on the process of attenuation is the spatial organization of the drainage watershed. Downstream hydrographs are a convolution of the spatial and temporal variations in flow inputs from throughout the watershed [Cudennec et al., 2002], known as the concept of the geomorphological unit hydrograph [Rodriguez-Iturbe and Valdes, 1979]. This accounts for the travel time of the flow from different parts of the watershed. The travel time is dependent upon both the geometry of the network structure and the flow hydraulics [Snell and Sivapalen, 1994], responsible for both geomorphological [Rinaldo et al., 1991] and hydrodynamic [Lighthill and Whitham, 1955] dispersion. Hydrodynamic dispersion accounts for the concept that precipitation falling on the same location at the same time may not reach the outlet at the same time. This is due to flow resistance caused by friction and attenuation caused by storage. Geomorphological dispersion explains how precipitation at the same time falling on different parts of the watershed arrives at the outlet at different times. This is caused by differential flow path lengths. These principles assert that the flood wave celerity remains spatially constant during an event, particularly when bankfull discharge (the discharge when the water elevation reaches the height of the banks) [Williams, 1978] is achieved. However, Saco and Kumar [2002] dispute this assumption stating that flow velocities exhibit nonlinearity in different parts of the river network. The fact that the flood wave celerity varies spatially throughout the network and over time introduces a third type of dispersion on the network travel times: kinematic dispersion.

Different subwatersheds will respond to rainfall in different ways due to differing watershed characteristics, in terms of both volume and rate of runoff. The synchronicity and sequencing of tributaries inflow to the main river is further complicated by the meteorological storm track. Singer and Dunne [2004] give an example where winter frontal rainfall results in flood conditions in certain subwatersheds but others are unaffected. Yet, it is this synchronicity that will be critical to attenuation: for example, if two tributary peak flows are coincident then the magnitude of river flow is increased, while if the subwatershed peak flows are desynchronized then this increase is likely to be smaller [Thomas and Nisbet, 2007]. Figure 1 illustrates two cases: (a) when a tributary peaks significantly before the main river and so does not contribute to the flood peak downstream and (b) when the peaks of the tributary and main river are much closer, meaning that the tributary does contribute to the peak flow downstream, and is higher in magnitude. It follows that if a particular land use in a given tributary is shown to influence high flows at one particular spatial scale, the extent to which this might impact larger spatial scales depends upon the location of that tributary with respect to other tributaries and may vary between hydrological events according to how the sequencing of storm tracks impacts upon tributary response. Impacts upon both flow magnitude and the timing of response will be critical.

Relatively few studies have quantified the effect of localized changes in watershed biophysical properties upon tributary timing and how this impacts upon downstream river flows. Acreman et al. [2003] for the River Cherwell in Oxfordshire U.K. found that both floodplain storage and channel restoration had the potential to attenuate flood hydrographs, but with only a negligible impact on peak flow magnitude and a greater impact on peak flow timing. JBA Consulting [2007] considered two tributaries responsible for flooding of the River Ure at Ripon, North Yorkshire, U.K. They recognized that the timing of the flood peaks and how the flows combined in the main river would influence the magnitude of the flood downstream. They found that while certain land management measures could significantly change flows in headwater bains, the impacts at larger scales were highly dependent upon the precise land management scenario and location of 


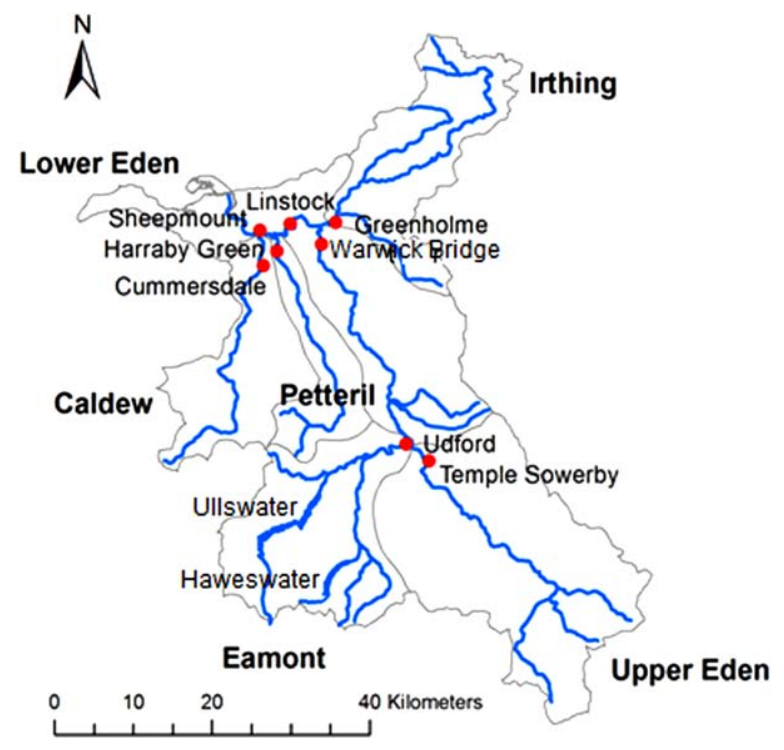

Figure 2. Location map of the Eden Watershed. The red dots show the location of the gauging stations used within this study. implementation. Thomas and Nisbet [2007] found that planting riparian woodland increased flood storage by $15-71 \%$ and that flood peaks could be delayed by 30-140 min as a result. In theory, this could either desynchronize or resynchronize tributary response according to where in a tributary, and in which tributary, the riparian woodland is planted. Lane and Milledge [2012] showed using a numerical model that while drainage of an upland watershed increased the rate of runoff and hence the timing of maximum flow in a flood event, it did not impact the level of runoff concentration and hence flood flow magnitude. While the watershed response was marginally earlier, the impacts of this response upon downstream

flood risk depended upon how this response changed with respect to other subwatersheds: the impacts of changing biophysical properties were relative and scale dependent.

In this paper, we take a different approach to the question of tributary timing effects. We focus upon a major river flood in a large watershed $\left(\sim 2400 \mathrm{~km}^{2}\right)$ in the north of England and use, primarily, numerical simulation to quantify how changes in tributary timing impact upon downstream flood magnitude. We aim to test the hypothesis that the timing of tributary response, a function of both the static organization of the watershed drainage network and the dynamic of individual flood events, can exert a significant impact upon downstream flood magnitude and hence flood risk. Our approach compliments statistical approaches [Lane, 2003] (I. Pattison et al., 2014, Spatial downscaling and sub-catchment prioritisation for managing river flows, submitted to Journal of Hydrology) that have shown for high river flows (with a daily discharge frequency of less than $1 \%$, including flood flows), substantial flow variability can be explained by differences in the relative timing of flow peaks.

\section{Methodology}

\subsection{Eden Watershed}

The focus of this paper is a major flood event (January 2005) in the city of Carlisle, on the River Eden in Cumbria U.K. The Eden watershed has an area of $2400 \mathrm{~km}^{2}$ and an average annual precipitation of $1183 \mathrm{~mm} \mathrm{a}^{-1}$ [Environment Agency, 2008]. It consists of six major subwatersheds; the Upper Eden, Eamont, Irthing, Caldew, Petteril, and main lower Eden (Figure 2). The Upper Eden at Temple Sowerby is the largest subwatershed $\left(616.4 \mathrm{~km}^{2}\right)$ and has several tributaries originating in the Howgill Fells and the Pennines. The River Eamont drains from the English Lake District and receives the highest rainfall in the whole watershed (1768 mm $\mathrm{yr}^{-1}$ ) and has geology of metamorphic volcanic rocks, which are very impermeable and lead to rapid runoff [Environment Agency, 2008]. This subwatershed is heavily regulated by the attenuating effect of Ullswater lake and the reservoir of Haweswater. The Irthing is the only main right bank tributary draining from the Northern Pennines and Border mires and is dominated by forestry. The Petteril is a lowland river and its watershed has improved pasture and arable agriculture as its main land use. This subwatershed experiences the lowest rainfall totals with $942 \mathrm{~mm} \mathrm{a}^{-1}$. Finally, the Caldew drains from the highest topography region in the watershed, the Skiddaw fells of the Lake District (950 m AOD) and consists of impermeable volcanic geology. The Eden watershed is therefore particularly diverse in terms of its climate, topography, soil types, geology, and land cover [Environment Agency, 2008]. This means that the drivers of watershed-scale flood risk are spatially variable, as rainfall/runoff inputs and response times are spatially variable.

The focus of this paper is the January 2005 flood event was the most extreme the watershed has ever experienced in the historical and measured record [Archer et al., 2007a, 2007b] dating back to 1770 which was 
reconstructed by Pattison and Lane [2012a], with the flood level in Carlisle being $1 \mathrm{~m}$ higher than the previous worst flood on record [Environment Agency, 2006]. The storm event that caused this flooding extended from the 6th to the 9th January 2005 and affected northern England, Southern Scandinavia, Germany, and the Baltic Region. The extreme nature of the event is linked to its duration, rather than the intensity of the rainfall. Overall, this storm has been estimated as having a return period of 50-100 years (0.02-0.01 annual probability) but resulted in a flood on the River Eden with a return period of greater than 100 years. The most significant rainfall was orographically forced, in the south of the watershed. Wet Sleddale in the Eamont subwatershed recorded $207 \mathrm{~mm}$ rainfall over the 3 days of the event, with a return period estimated at $\sim 170$ years $(0.58 \%)$. This rainfall resulted in an extreme hydrological response, with all river systems experiencing high flows demonstrating the spatially extensive high magnitude rainfall experienced in this event, rather than the effects localized high intensity precipitation. A total of 2016 properties were flooded throughout the watershed, of which 1865 were in the city of Carlisle. The total economic cost of the flood was between $£ 350$ million and $£ 400$ million [Environment Agency, 2006] at 2005 prices.

\subsection{Statistical}

To assist with the interpretation of the hydraulic model results, a data set of 134 high flow events were obtained from the Sheepmount gauging station in Carlisle (Figure 2), for the period 1977-2007. These were defined as events that exceed the threshold of $347 \mathrm{~m}^{3} \mathrm{~s}^{-1}$, corresponding to a frequency of $1 \%$ or less in terms of daily mean flow. These data have been subject to an intensive statistical analysis (Pattison et al., submitted manuscript), focusing upon the magnitude and timing of peak high flows (and not just floods). Relative timing was calculated by subtracting the time of the peak flow in the subwatershed from the time of peak flow downstream in the main Lower Eden at Carlisle. Here, we use this data set to contextualize the 2005 flood. Initial analysis showed that the January 2005 flood event was significantly different to all other 134 events in this record, with the peak discharge $\left(1516 \mathrm{~m}^{3} \mathrm{~s}^{-1}\right)$ through the city of Carlisle being $304 \%$ of the long-term average of the peak-over-threshold (POT) events between 1977 and 2007, and so additional analyses were employed to try and explain this difference. First, the average peak discharge was calculated for all the tributaries and the main stem. The deviation from this average was calculated for the January 2005 event, and expressed as a percentage. This was done in terms of both peak magnitudes and relative timing. Second, the relative timing of the peak flows is affected by both the speed of the flood wave and the distance between the subwatershed and Carlisle. Therefore, the speed of flood wave propagation, wave celerity $(C)$ is calculated from:

$$
\mathrm{C}=\delta \mathrm{x} / \delta \mathrm{t}
$$

where $\delta x$ is the longitudinal distance and $\delta t$ is the time difference. Use of these basic data helped to contextualize the January 2005 event.

\subsection{Hydraulic Modeling}

A watershed-scale hydraulic model, which incorporates the major tributaries of the Upper Eden, Eamont, Irthing, Petteril, and Caldew was constructed in iSIS-Flow, a standard 1-D hydraulic model (Halcrow, iSIS Guide). iSIS-Flow can be applied to open channel systems where discharge and stage can be simulated. Hydraulic units such as channel cross sections and structures, e.g., bridges and weirs form the basis of the model structure, with upstream and downstream boundary conditions necessary to initiate a hydrograph and convert stage to discharge respectively. Confluences are represented by junction units which are governed by the continuity of flow and equality of water surface level equations (iSIS Manual, Halcrow). The iSIS-Flow model was modified from an existing hydraulic model developed for the Environment Agency of England and Wales for the Eden [Atkins, 2005]. The upstream boundary condition for each tributary was the respective hydrograph from the January 2005 flood event. The model was validated using gauged data from the Sheepmount, Linstock, and Great Corby gauging stations. Calibration for this event was optimized by the peak stage at Sheepmount. Figure 3 shows the process by which the model was calibrated. The Manning's $n$ roughness parameter was changed within, before or after Carlisle. Increasing Manning's $n$ will increase the flow resistance meaning that stage increases locally for a given discharge. Therefore when $n$ is increased downstream of Carlisle water is backed-up and stage increases in the centre of Carlisle. The optimum calibrated model was achieved through increasing $n$ by 0.01 within and before Carlisle (Figure 4). The performance of the calibrated model is indicated by the following statistics: (a) percentage error in 

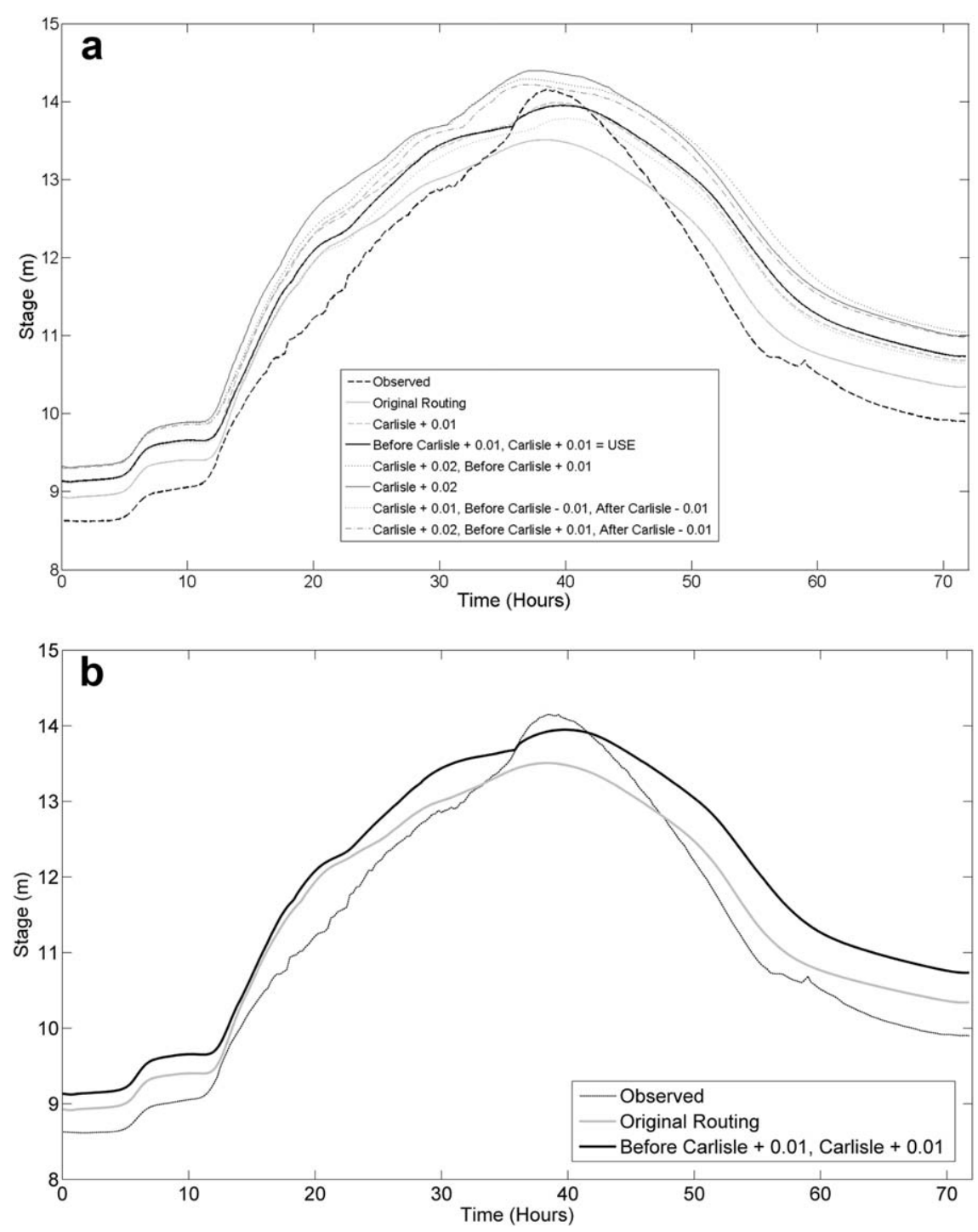

Figure 3. Sensitivity analysis of Sheepmount hydrograph to Manning's $n$. Simulations represent changing Manning's $n$ in different reaches of Eden, e.g., U/S tribs (before -0.01 , Carlisle $+0.01=$ Manning's $n$ decreased by 0.01 before Carlisle and increased by 0.01 in Carlisle itself. Calibration of Eden iSIS model using downstream gauging station of Sheepmount in Carlisle to optimize for flood peak. (Performance statistics - Nash Sutcliffe Coefficient $=0.85, \mathrm{RMSE}=0.67 \mathrm{~m}, \%$ error peak stage $=-1.45 \%$, $\%$ error in volume $=5.2 \%$.)

predicted flow magnitude of $-1.5 \%$ (equivalent to $-0.20 \mathrm{~m}$ of flow stage) and $+0.03 \%$ in flow timing (1.25 h); (b) Nash Sutcliffe Coefficient $=0.85$; (c) RMSE $=0.67 \mathrm{~m}$; and (d) $\%$ error in volume $=5.2 \%$ ).

Internal model validation was also assessed at two other gauging stations. At Great Corby, the model also performs relatively well, with an error of $0.079 \mathrm{~m}$ and $0.83 \mathrm{~h}$ on the magnitude and timing of the peak stage. This corresponded to a $1.8 \%$ error in terms of peak discharge. However, at Linstock the model performs less well, with an error of $0.59 \mathrm{~m}$ and $1.83 \mathrm{~h}$. The difficulty in using this stations gauged data are highlighted by two limitations. First, there were problems with the recording of the event at Linstock, with instrumentation failing during the event just after the peak stage. Second, there is no rating curve at Linstock to assess the effect on flow. The errors reported here provide a qualitative indication of the magnitudes of change in predicted flow necessary during the experiment for there to be some confidence that real changes are being identified.

The general approach to the hydraulic modeling experiment consisted of changing tributary input systematically in terms of both the magnitude $(0.5 \%, 1 \%, 2 \%, 5 \%, 10 \%, 15 \%, 20 \%$, and $25 \%$ reductions) of the flows and the timing ( 15 minutes, 30 min, 1 h, 2 h, 3 h, 4 h, 6 h, 8 h earlier and later) of the flows for individual 

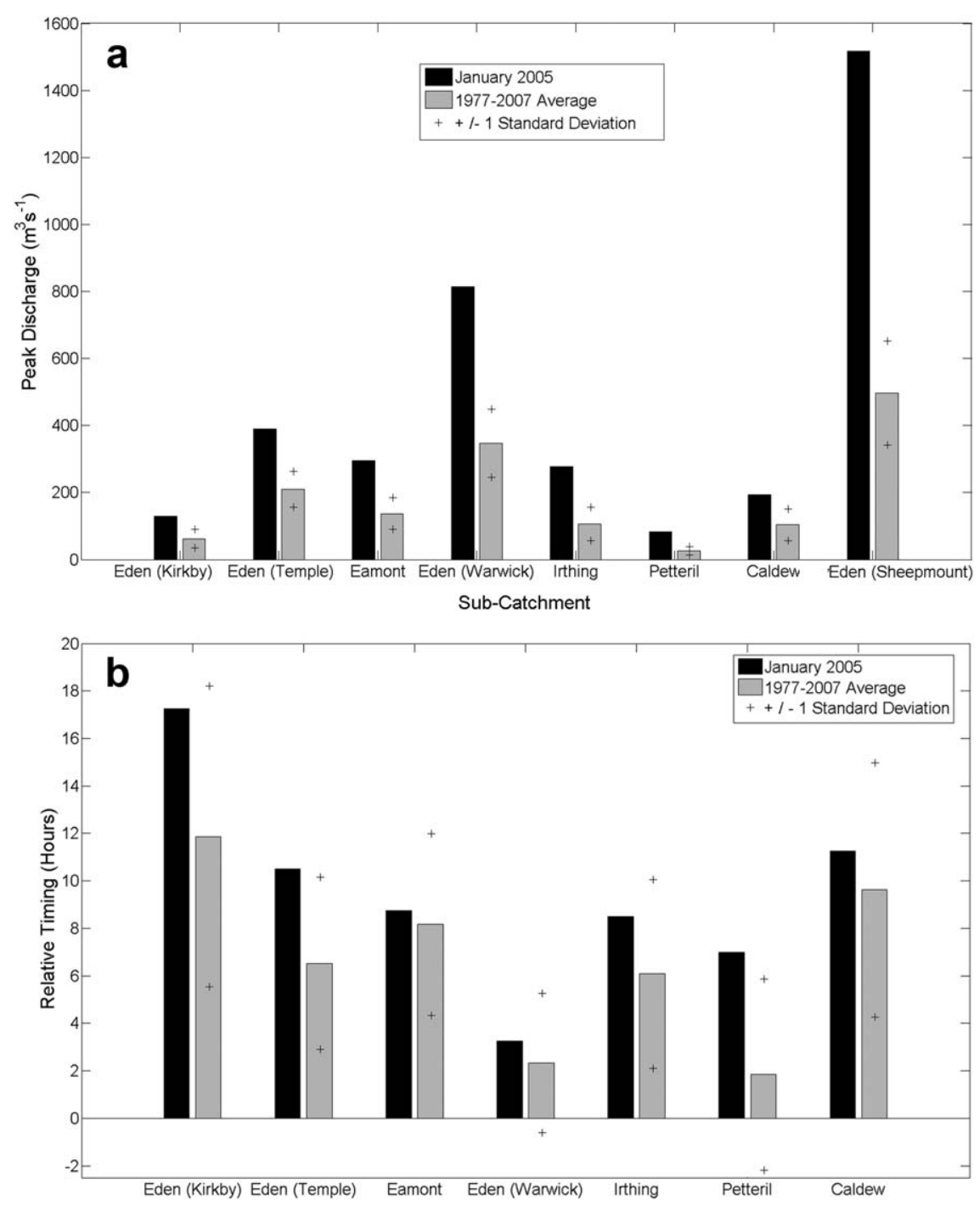

Figure 4. Comparison of the January 2005 flood with the long-term average in terms of peak magnitudes from each subwatershed. Comparison of the January 2005 flood with the long-term average in terms of the peak flow relative timing from each subwatershed with respect to Carlisle. A value of 0 means that both the tributary and the downstream main river peak at the same time.

tributaries. In practice, the process of attenuation does not function by just delaying and reducing the peak flow, it changes the shape of the hydrograph. Therefore, the hydrograph was also be stretched in the terms of time and squashed in terms of flow magnitude simultaneously, through using change factors:

$$
\begin{gathered}
\text { Magnitude }=\text { Original } \times \text { Change factor } \\
\text { Time }=\text { Original } \div \text { Change factor }
\end{gathered}
$$

Use of these change factors, unlike simple changes in magnitude and timing, conserves flood volume while changing attenuation.

Scenarios involving more than one of the major tributaries were also tested, and experiments were undertaken that included both timing and magnitude shifts from the same tributary simultaneously. This was because it is hypothesized that it may be easier to change the flows from more than one subwatershed by a smaller amount and still achieve the same effect as shifting one subwatershed by a large amount. 


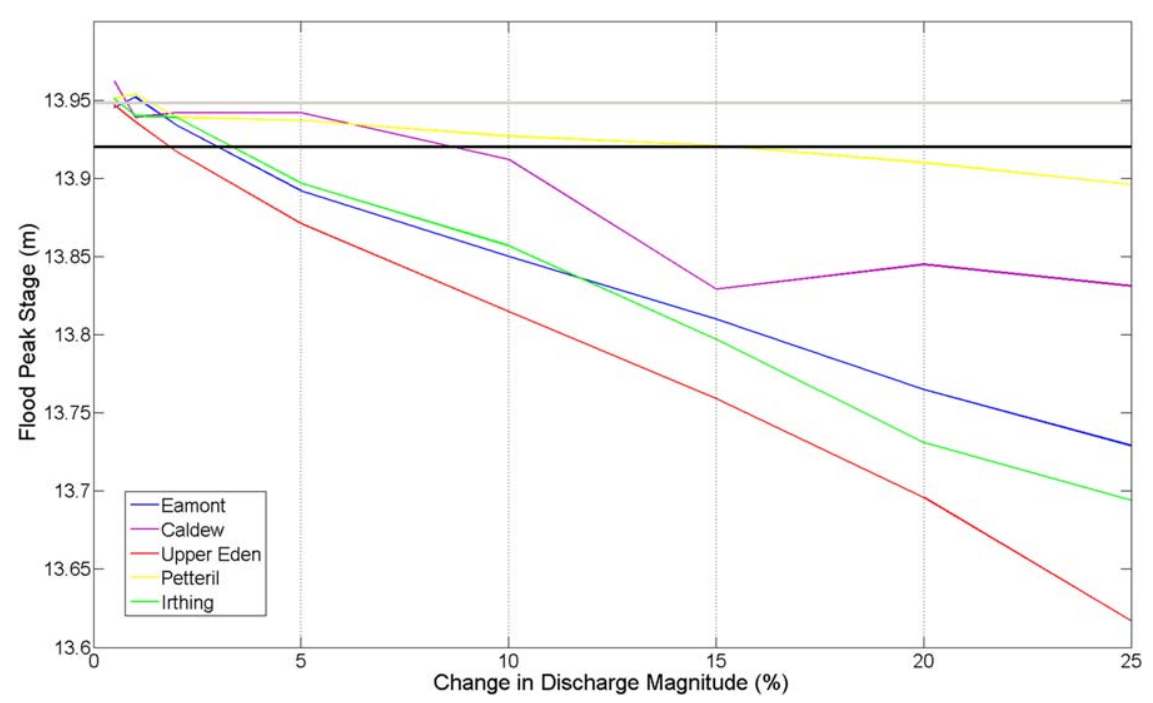

Figure 5. Sensitivity of peak stage at Carlisle (Sheepmount) to percentage decreases in subwatershed hydrograph contributions.

\section{Results}

\subsection{The 2005 Event in a Statistical Context}

The peak discharge through the city of Carlisle as measured by the Sheepmount gauging station was $1516 \mathrm{~m}^{3} \mathrm{~s}^{-1}, 304 \%$ of the long-term average of the РОT events between 1977 and 2007 (those $>347 \mathrm{~m}^{3}$ $\mathrm{s}^{-1}$; Figure 5). Possible causes for this extreme flood in terms of the contributing subwatersheds are that: (1) a specific subwatershed had an extreme response to rainfall and caused a large flood downstream; or (2) that all the subwatersheds responded with greater than average peak flows; or (3) that individual tributary responses were synchronized. The data show that the Petteril tributary deviated most from the long-term average, with a 2005 peak magnitude on the Petteril being 335\% of the long-term average. However, this was still the lowest actual contribution $\left(82.6 \mathrm{~m}^{3} \mathrm{~s}^{-1}\right)$ from any of the major subwatersheds. The Irthing contribution was $282 \%$ of the long-term average, while the contribution from the Caldew (187\%), Eamont $(215 \%)$, and Upper Eden (Kirkby Stephen $=209 \%$, Temple Sowerby $=187 \%$ ) were all about double the long-term average peak flow. This highlights the importance of scale in causing extreme floods in this

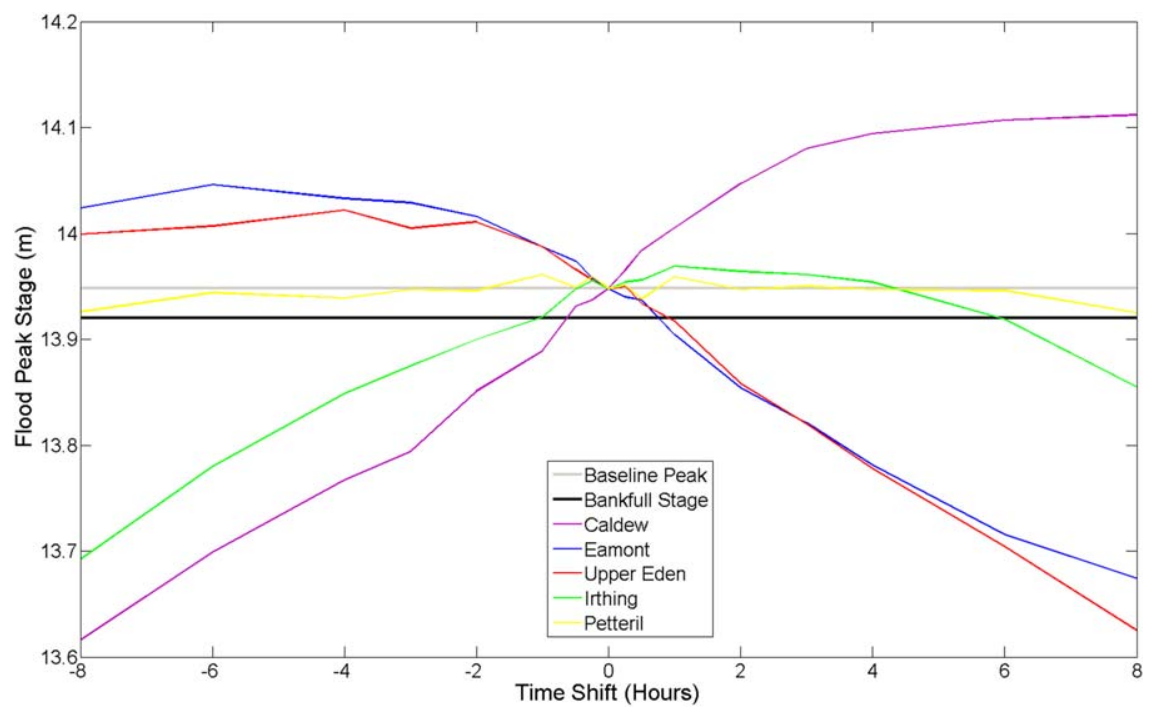

Figure 6. Sensitivity of peak stage at Carlisle (Sheepmount) to timing shifts of the contributing subwatershed's hydrograph—light gray line = original peak flow, dark gray line = bank full. 
Table 1. Celerity of Flood Wave as Calculated From the Travel Time Between the Flood Peak at Each Station and Carlisle and the Associated Distance

\begin{tabular}{lcccc} 
Tributary Celerity & Distance $(\mathrm{km})$ & $\begin{array}{c}\text { Mean Wave } \\
\text { Celerity }\left(\mathrm{km} \mathrm{h}^{-1}\right)\end{array}$ & $\begin{array}{c}\text { Jan } \\
\text { Celerity }\left(\mathrm{km} \mathrm{h}^{-1}\right)\end{array}$ & 5.81 \\
\hline Upper Eden (Kirkby Stephen) to Carlisle & 100.2 & 9.90 & 5.90 & $-41.3 \%$ \\
Upper Eden (Temple Sowerby) to Carlisle & 61.9 & 10.18 & 6.83 & $-42.0 \%$ \\
Eamont to Carlisle & 59.8 & 11.81 & 5.29 & $-42.2 \%$ \\
Main Eden (Warwick Bridge) to Carlisle & 17.2 & 5.96 & 1.33 & $-11.2 \%$ \\
Irthing to Carlisle & 17.3 & 2.80 & 0.91 & $-52.5 \%$ \\
Petteril to Carlisle & 6.4 & 1.54 & 0.51 & $-40.9 \%$ \\
Caldew to Carlisle & 5.7 & 0.86 & & $-40.7 \%$ \\
\hline
\end{tabular}

example: all subwatersheds were contributing large flows, associated with a synoptically coherent rainfall event. The sum of the contributing tributary peak discharges for the 2005 event was $1239 \mathrm{~m}^{3} \mathrm{~s}^{-1}$ which is $18.3 \%$ lower than the actual peak discharge downstream in Carlisle. This suggests a high level of tributary synchronicity as the sum of the average tributary peak discharges is $581.7 \mathrm{~m}^{3} \mathrm{~s}^{-1}$ which is $16 \%$ greater than the average flood discharge in Carlisle.

The question that remains is the extent to which the effects of synoptic coherence were exacerbated by the relative timing of response of the major tributaries, with respect to the downstream gauging station of Sheepmount in Carlisle: to what extent does interaction of the flows from each subwatershed (i.e., synchronicity), exacerbate the effects of tributary synchronicity? The timing of the Eamont was not significantly different to the long-term average (107\%; Figure 6). However, the timing of the Upper Eden was earlier than in the long-term average flood by $4-5 \mathrm{~h}$. This meant that the sequencing of the Eamont and Upper Eden was switched around, so that the Upper Eden peaked much earlier and much closer in time to the Eamont. Due to the proximity of the gauging stations on each of these rivers, it can be assumed that peak flows coincided and flowed down the Middle Eden together. Table 1 shows that both these tributaries had a higher flood wave celerity than the other tributaries. This makes it likely that the peak flow from the upstream subcatchments were synchronous with the lower subcatchments peak flows resulting in this extreme downstream flood.

The Petteril also seemed to peak significantly earlier $(7 \mathrm{~h})$ than during other smaller floods with respect to the flow gauge at Sheepmount in Carlisle. The Petteril also peaks earlier with respect to the all other subwatersheds. These changes combined to reverse the sequencing of flow combination in and upstream of Carlisle. Normally, the Petteril peaks just after the Eden, and the flows combine in Carlisle. In the 2005 event, the Petteril peaked about $3.75 \mathrm{~h}$ before the main Eden, maintaining high flows in Carlisle for a longer period, but the discharge was not as high as would have occurred under the normal situation, with the Petterill peaking just after the Eden. All other subwatersheds peaked earlier than during the long-term average flood, but the sequencing stayed the same. This evidence emphasizes that synchronicity is a complex relative process: the change in timing of the Upper Eden may have exacerbated the peak flow magnitude at Carlisle, but the earlier response of the Petteril may have reduced it.

Relative timing can also be considered in terms of the celerity of the flood wave. Table 1 compares the mean wave speed propagation rates downstream (celerity) to the celerity of the flood waves from the different tributaries for the January 2005 flood event. First, considering how different tributaries compare to each other in the average event, it is clear that the upper subwatersheds (Upper Eden and Eamont) have significantly higher flood wave celerity than the lower subwatersheds (Irthing, Petteril, and Caldew), and reflecting the steeper valley slopes of the upper subwatersheds. The reduction in mean wave celerity calculated for Warwick Bridge to Carlisle reflects the onset of significant attenuation from Temple Sowerby downstream, reflecting the onset of floodplain storage, known to occur from the Middle Eden (Temple Sowerby) downstream.

Second, during the January 2005 flood event, the propagation of the flood wave from each of the tributaries was slower than during the average flood event, by a significant degree $(>40 \%)$ in most cases. The major exception is the lowest reach (downstream of Warwick Bridge) which had a very similar flood wave celerity to the average event. Knight and Shiono [1996] investigated the effect on flood wave celerity of inchannel and out-of-bank flows, showing that lag time decreases (and celerity increases) with increasing in- 
channel discharges and lag time increases (celerity decreases) once out-of-bank discharge begins. Table 1 implies that all the tributaries flood waves were experiencing out-of-bank storage and attenuation between their confluences and the city of Carlisle.

\subsection{Hydraulic Model Results}

First, the effect of changing tributary discharge magnitudes on downstream (Carlisle, Sheepmount) peak stages is assessed in Figure 7. The maximum reduction in peak stage $(0.33 \mathrm{~m})$ in Carlisle was caused by a $25 \%$ reduction in the flows from the Upper Eden. Figure 7 suggests that the Upper Eden is always the most effective at reducing downstream stage, as it has the largest flow contribution of all the sub-s in actual discharge terms. The Irthing and Eamont offer similar amounts of flood stage reduction downstream $(0.25$ and $0.21 \mathrm{~m}$, respectively). At lower percentage flow reductions, the Eamont is more effective than the Irthing, but with greater than $10 \%$ flow reduction the Irthing becomes more beneficial. The Caldew has very little impact on peak stage in Carlisle until it is decreased by more than 10\%. However, for greater than 15\% flow decreases, the Caldew has no further impact on peak stage downstream in Carlisle. Reducing the flow contribution of the Petteril has very little effect on peak stage at Carlisle, with a $25 \%$ reduction in the magnitude of the Petteril flows only resulting in a $0.05 \mathrm{~m}$ reduction in the peak stage downstream. This is because the flows of the Petteril are lowest in actual terms.

It is important to take account of the error associated with the model. The baseline simulation had a $0.20 \mathrm{~m}$ error on the peak stage at Carlisle. To determine whether any of these change scenarios result in no out-ofbank flow, the error has to be subtracted from the bankfull level (solid black line). The threshold for the flow to be contained within the channel taking into account the error of the model is $13.71 \mathrm{~m}$. The only magnitude change scenarios which result in a peak stage less than the bankfull are the Upper Eden $25 \%$ and $20 \%$ and the Irthing $25 \%$.

Second, the effect of changing tributary peak flow timing on downstream (Carlisle) peak stages was assessed. These consisted of the hydrograph being shifted by the timings ranging from 0.25 to $8 \mathrm{~h}$, and the results are shown in Figure 8 . The effect of changing the timing of the Petteril has a minimal effect on the peak stage. Delaying the upper subwatersheds (Upper Eden and Eamont) reduces peak stage. When these tributaries peak earlier, peak stage increases. The longer these tributaries are delayed, the greater the reduction in peak stage downstream. Delaying these tributaries has a similar effect on peak flow in Carlisle up to a delay of $6 \mathrm{~h}$ with peak stage reductions of 0.24 and $0.23 \mathrm{~m}$, respectively. However, a delay of $8 \mathrm{~h}$ of the Upper Eden has a greater effect than the same shift on the Eamont, with a 0.32 and $0.27 \mathrm{~m}$ reduction in peak stage, respectively. The effect of these tributaries peaking earlier is for peak stage downstream to increase by $0.05 \mathrm{~m}$ for the Upper Eden and $0.08 \mathrm{~m}$ for the Eamont.

The effect of speeding up the response of the Caldew by $8 \mathrm{~h}$ is the same as caused by delaying the Upper Eden by $8 \mathrm{~h}$ : a peak stage reduction of $0.33 \mathrm{~m}$. Delaying the Caldew results in higher peak stages at Carlisle, with an increase of $0.16 \mathrm{~m}$ with an $8 \mathrm{~h}$ delay. Similar trends are shown for the Irthing, with a $0.26 \mathrm{~m}$ decrease in peak stage when the Irthing is speeded up by $8 \mathrm{~h}$. However, a more complex trend is evident when the Irthing is delayed. A delay of up to $4 \mathrm{~h}$ leads to a slight increase in peak stage downstream, with the effect of a $1 \mathrm{~h}$ delay having the greatest impact on stage. However, a delay of greater than $4 \mathrm{~h}$ leads to a decrease in peak stage in Carlisle. An $8 \mathrm{~h}$ delay of the Irthing results in a $0.09 \mathrm{~m}$ decrease in peak stage downstream.

The error associated with the baseline model is $0.20 \mathrm{~m}$ error on the peak stage at Carlisle, resulting in a threshold for overbank flow of $13.71 \mathrm{~m}$. It is evident that significant changes in the timing of the tributaries are needed to lead to peak stages below this threshold. First, a $6 \mathrm{~h}(13.70 \mathrm{~m})$ and $8 \mathrm{~h}(13.62 \mathrm{~m})$ delay of the Upper Eden results in a peak stage in Carlisle within bank. An $8 \mathrm{~h}$ delay of the Eamont is required, resulting in a peak stage of $13.67 \mathrm{~m}$. Other scenarios that lead to no out-of-bank flow are when the Caldew peaks $6 \mathrm{~h}$ $(13.69 \mathrm{~m})$ or $8 \mathrm{~h}(13.61 \mathrm{~m})$ earlier or the Irthing peaks $8 \mathrm{~h}$ earlier $(13.69 \mathrm{~m})$.

The uncertainties associated with these scenarios were evaluated by assessing the sensitivity of the peak stage downstream to the roughness of the channel cross sections. This type of uncertainty analysis is more common and developed in the application of hydrological models rather than hydraulic models. For this reason, as well as the instability of the hydraulic model under certain parameterizations and scenarios, a basic experiment is carried out for the most extreme of the scenarios reported in this paper (i.e., $25 \%$ 

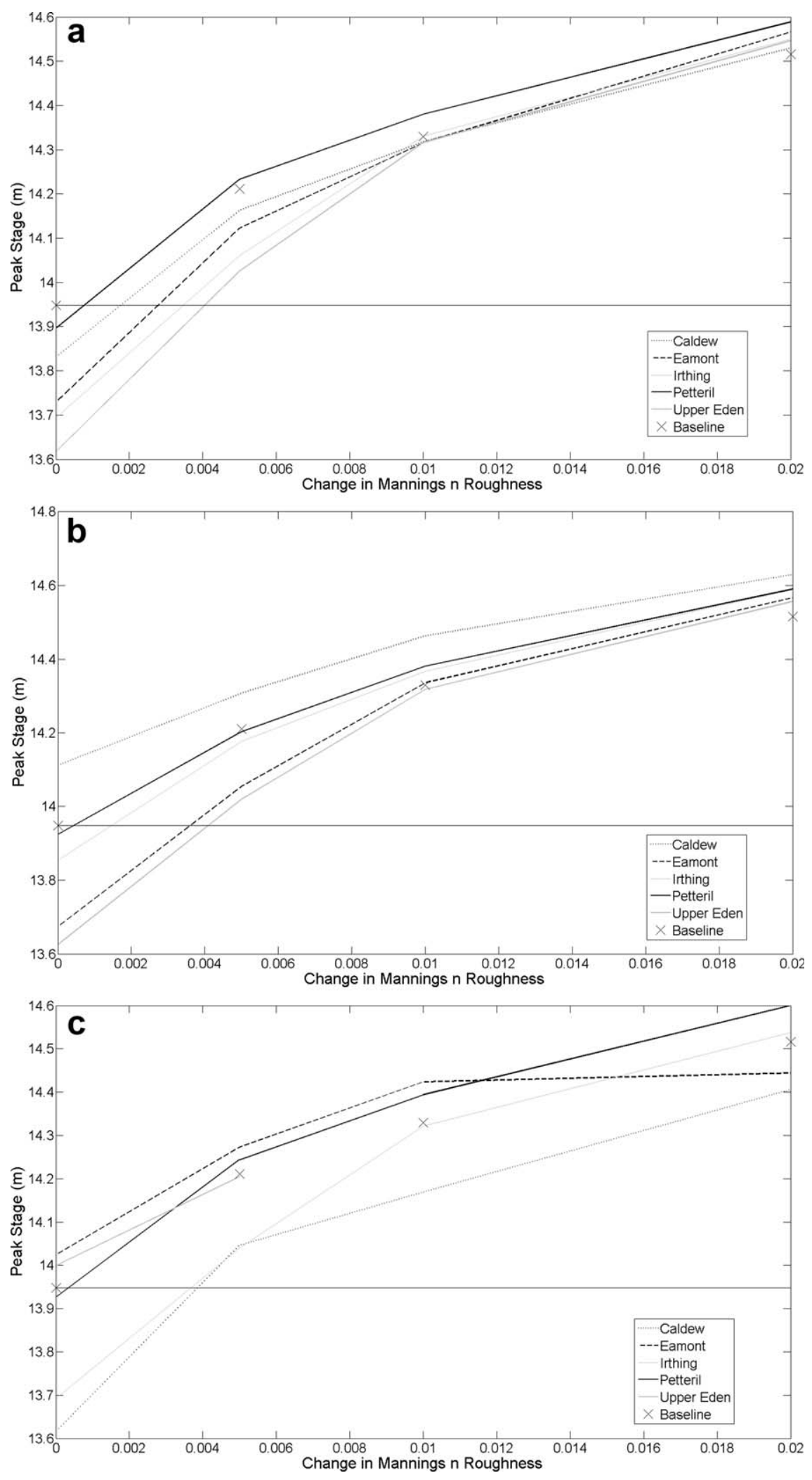

Figure 7. Uncertainty analysis of tributary $25 \%$ magnitude reduction scenario and Mannings $\mathrm{n}$. Uncertainty analysis of tributary $8 \mathrm{~h}$ delay scenario and Mannings $\mathrm{n}$. Uncertainty analysis of tributary $8 \mathrm{~h}$ earlier time scenario and Mannings $\mathrm{n}$. 


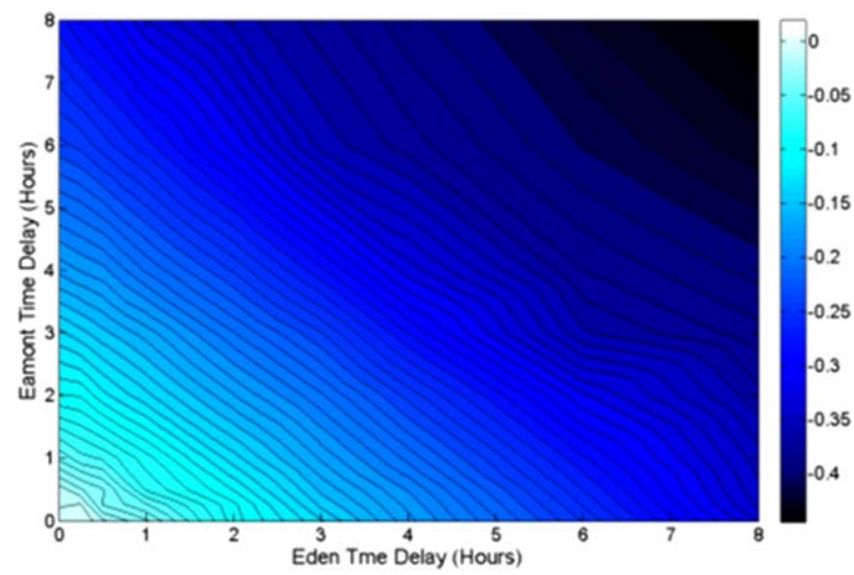

Figure 8. Sensitivity of peak stage at Sheepmount to timing shifts from multiple subwatersheds. magnitude reduction, $8 \mathrm{~h}$ delay/ earlier) for the most common calibration parameter in a hydraulic model; Mannings $\mathrm{n}$ for the values of $+0.005,+0.01$, and +0.02 . Results for these simulations are shown in Figure 9 (Magnitude), 7b (Time delay), and 7b (Earlier time). The significant outcomes of this uncertainty analysis are first that the hydraulic model is more sensitive to Mannings roughness than it is to the hydrograph boundary conditions. The range of peak stages between the different tributary scenarios is much smaller than it is for the

roughness sensitivity analysis. Second, as the Mannings $\mathrm{n}$ value increases globally throughout the whole network, the difference between the scenarios for the different tributaries decreases. However, for small changes in roughness $(+0.005)$ the relative order of the tributary scenarios stays the same. Although basic, this uncertainty analysis suggests that results are uncertain depending on the choice of Mannings n. However, the baseline value of $\mathrm{n}$ used in the analysis reported gives the best match with the observed gauged data, and are most physically representative for the river channel network.

Scenarios for multiple subwatershed timings (Upper Eden and Eamont) were then tested. Results, in terms of the effect of timing on peak stage downstream at Carlisle are shown in Figure 8. This shows that the maximum stage reduction is achieved by a time delay of both tributaries by $8 \mathrm{~h}$ in combination $(0.44 \mathrm{~m})$. The same effect of delaying one of the tributaries by $8 \mathrm{~h}$ can be achieved by delaying both tributaries by $4 \mathrm{~h}$ each $(0.32 \mathrm{~m})$. The combination of different timing delays from both the Eden and Eamont together sometimes provides additional benefits over when the stage reduction caused by each tributary in isolation are added together. This synergy means that smaller changes in both subwatersheds may be equal to larger shifts from just one tributary. This is the case for the scenarios which include any time delay of one of the tributaries in addition to a lower time delay for the other ( $\leq 1 \mathrm{~h}$ for the Eden and $\leq 0.50 \mathrm{~h}$ for the Eamont). This is important given the expected ease of achieving smaller delays through changes in watershed-scale biophysical properties. When both tributaries are delayed by larger amounts the amount of peak stage reduction in Carlisle is less than the separate effects of delaying each tributary added together. The same effect downstream can be achieved by smaller time delays of both tributaries simultaneously or a longer time delay of just one of the rivers. For example, an hour delay of the Eden results in a $0.03 \mathrm{~m}$ reduction of the peak stage at Carlisle, while a half hour delay of both tributaries together results in a $0.03 \mathrm{~m}$ decrease.

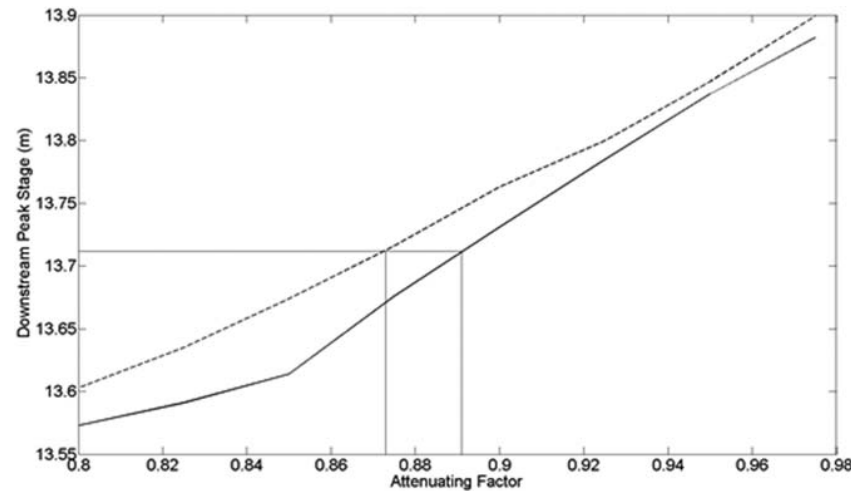

Figure 9. Impact of varying degrees of attenuation of peak stage at Sheepmount. Dashed line for Upper Eden, Solid line for Eamont. Attenuating factors for bankfull stage are marked.
At low time delays $(<5 \mathrm{~h})$ both tributaries are both as effective as each other in terms of the effect of delaying their flow. However, for longer delays, the impacts are variable between tributaries. In scenarios where the time delay of the Eden is high ( $>6$ h), downstream flood stage is more sensitive to the Eamont if it is delayed by more than $3 \mathrm{~h}$. This means that beyond $6 \mathrm{~h}$ delay of the Eden, the peak stage in Carlisle decreases more per unit time delay greater than 


\begin{tabular}{|c|c|c|c|c|c|c|c|}
\hline Timing Magnitude & $\mathrm{Oh}$ & $0.25 \mathrm{~h}$ & $0.50 \mathrm{~h}$ & $1 \mathrm{~h}$ & $2 \mathrm{~h}$ & $4 \mathrm{~h}$ & $8 \mathrm{~h}$ \\
\hline $0 \%$ & 0 & 0.002 & -0.014 & -0.031 & -0.09 & -0.17 & -0.323 \\
\hline $2 \%$ & -0.031 & $\begin{array}{c}-0.044 \\
(-0.029)\end{array}$ & $\begin{array}{c}-0.053 \\
(-0.045)\end{array}$ & $\begin{array}{c}-0.069 \\
(-0.062)\end{array}$ & $\begin{array}{l}-0.114 \\
(-0.121)\end{array}$ & $\begin{array}{l}-0.193 \\
(-0.201)\end{array}$ & $\begin{array}{l}-0.339 \\
(-0.354)\end{array}$ \\
\hline $5 \%$ & -0.077 & $\begin{array}{c}-0.085 \\
(-0.075)\end{array}$ & $\begin{array}{c}-0.092 \\
(-0.091)\end{array}$ & $\begin{array}{l}-0.106 \\
(-0.108)\end{array}$ & $\begin{array}{l}-0.143 \\
(-0.167)\end{array}$ & $\begin{array}{l}-0.218 \\
(-0.247)\end{array}$ & $\begin{array}{l}-0.349 \\
(-0.400)\end{array}$ \\
\hline $10 \%$ & -0.133 & $\begin{array}{c}-0.141 \\
(-0.131)\end{array}$ & $\begin{array}{c}-0.148 \\
(-0.147)\end{array}$ & $\begin{array}{c}-0.167 \\
(-0.164)\end{array}$ & $\begin{array}{l}-0.198 \\
(-0.223)\end{array}$ & $\begin{array}{l}-0.274 \\
(-0.303)\end{array}$ & $\begin{array}{l}-0.367 \\
(-0.456)\end{array}$ \\
\hline $25 \%$ & -0.331 & $\begin{array}{c}-0.332 \\
(-0.329)\end{array}$ & $\begin{array}{l}-0.335 \\
(-0.345)\end{array}$ & $\begin{array}{l}-0.34 \\
(-0.362)\end{array}$ & $\begin{array}{l}-0.352 \\
(-0.421)\end{array}$ & $\begin{array}{l}-0.377 \\
(-0.501)\end{array}$ & $\begin{array}{l}-0.419 \\
(-0.654)\end{array}$ \\
\hline
\end{tabular}

${ }^{a}$ Top value is the simultaneous scenario, bottom value is the two separate scenario effects added together. (Bold values indicate scenarios when the simultaneous scenario gives extra peak stage reduction than the two separate scenarios added together.)

$3 \mathrm{~h}$ of the Eamont than the Eden. However, in scenarios where the time delay of the Eden is less than $6 \mathrm{~h}$, downstream flood stage is more sensitive to the Eden when the Eamont is delayed by more than $5 \mathrm{~h}$. This means that for a time delay of the Eden by less than $6 \mathrm{~h}$ and a time delay of the Eamont by more than $5 \mathrm{~h}$, the peak stage in Carlisle decreases more per unit time delay of the Eden than the Eamont.

Changes in watershed-scale biophysical properties would not alter the magnitude or timing of the flow response in isolation, but the size and shape of the hydrograph in combination. Therefore, scenarios of combined magnitude and timing shifts were made for the Upper Eden and Eamont. The effect of shifts in timing and magnitude for the Upper Eden are shown in Table 2. The maximum peak stage reduction at Carlisle is $0.42 \mathrm{~m}$, caused by an $8 \mathrm{~h}$ delay and a $25 \%$ decrease in magnitude. For scenarios with timing delays less than $5 \mathrm{~h}$ and magnitude reductions of less than $10 \%$, the effect on downstream peak stage is equally sensitive to timing and magnitude changes in the Upper Eden. The importance of timing delays increases after $5 \mathrm{~h}$, with peak stage reduction being more sensitive to changes to timing than magnitude above this threshold. This means that beyond $5 \mathrm{~h}$ delay of the Eden, the peak stage in Carlisle decreases more per unit time delay than per percentage decrease of flow magnitude. The sensitivity of downstream flood stage to magnitude shift is high for shifts greater than $20 \%$ when the Upper Eden is shifted in time by less than $5 \mathrm{~h}$. This means that changes of flow magnitude beyond $20 \%$ have a greater effect on downstream peak stage than large changes in the timing of that flow.

The combinations of different timing and magnitude shifts sometimes produce added benefit to both the scenarios separately. The scenarios that fit this criterion are shown in bold font in Table 2 . This suggests that small time delays $(\leq 1 \mathrm{~h})$ in addition to any magnitude reduction combined provide more than the expected level of peak stage decrease downstream, than if either time delay or flow magnitude reduction were implemented separately. The greatest gain is for the smallest magnitude increase and smallest time delay ( $2 \%$ magnitude, 0.25 h), with $0.01 \mathrm{~m}$ extra stage decrease in Carlisle. However, for the scenarios combining larger magnitude decreases and time delays, less than the expected stage decrease is found downstream, with a $25 \%$ decrease in magnitude causing $0.33 \mathrm{~m}$, and an $8 \mathrm{~h}$ delay causing $0.32 \mathrm{~m}$ separately, but in combination they only cause a $0.42 \mathrm{~m}$ decrease in downstream peak stage instead of $0.65 \mathrm{~m}$.

The effect of shifts in timing and magnitude for the Eamont are shown in Table 3. The maximum peak stage reduction at Carlisle is $0.38 \mathrm{~m}$, caused by an $8 \mathrm{~h}$ delay and a $25 \%$ decrease in magnitude. This indicates that the peak stage at Carlisle is more sensitive to changes in the flows (both magnitude and timing) of the Upper Eden than the Eamont. Downstream flood stage reduction is more sensitive to the timing than the magnitude for lower magnitude changes. This means that smaller changes in the timing of the hydrograph have a greater impact on downstream stage than changes in the magnitude of the flows from the Eamont. This is a particularly useful finding as it is expected that delivering time delays (e.g., through encouraging floodplain storage) will be easier than changing the flow magnitude through land management changes. However, for higher magnitude changes ( $>20 \%$ ), magnitude becomes more important than the timing of the peak in impacting downstream peak stage, especially for small time delays.

Scenarios that combine both magnitude decreases and time delays of the Eamont have an added benefit for downstream flood stage as compared with the expected reduction from each separate scenario added together. A magnitude decrease of $2 \%$, combined with any of the timing delays, produces a peak stage 


\begin{tabular}{|c|c|c|c|c|c|c|c|}
\hline Timing Magnitude & $\mathrm{Oh}$ & $0.25 \mathrm{~h}$ & $0.50 \mathrm{~h}$ & $1 \mathrm{~h}$ & $2 \mathrm{~h}$ & $4 \mathrm{~h}$ & $8 \mathrm{~h}$ \\
\hline $0 \%$ & 0 & -0.008 & -0.011 & -0.044 & -0.094 & -0.167 & -0.274 \\
\hline $2 \%$ & -0.014 & $\begin{array}{c}-0.028 \\
(-0.022)\end{array}$ & $\begin{array}{c}-0.042 \\
(-0.025)\end{array}$ & $\begin{array}{c}-0.066 \\
(-0.058)\end{array}$ & $\begin{array}{c}-0.109 \\
(-0.108)\end{array}$ & $\begin{array}{c}-0.181 \\
(-0.181)\end{array}$ & $\begin{array}{c}-0.294 \\
(-0.288)\end{array}$ \\
\hline $5 \%$ & -0.056 & $\begin{array}{l}-0.061 \\
(-0.064)\end{array}$ & $\begin{array}{c}-0.075 \\
(-0.067)\end{array}$ & $\begin{array}{l}-0.091 \\
(-0.100)\end{array}$ & $\begin{array}{l}-0.126 \\
(-0.150)\end{array}$ & $\begin{array}{l}-0.196 \\
(-0.223)\end{array}$ & $\begin{array}{l}-0.316 \\
(-0.330)\end{array}$ \\
\hline $10 \%$ & -0.098 & $\begin{array}{c}-0.107 \\
(-0.106)\end{array}$ & $\begin{array}{c}-0.112 \\
(-0.109)\end{array}$ & $\begin{array}{l}-0.13 \\
(-0.142)\end{array}$ & $\begin{array}{l}-0.165 \\
(-0.192)\end{array}$ & $\begin{array}{l}-0.233 \\
(-0.265)\end{array}$ & $\begin{array}{l}-0.341 \\
(-0.372)\end{array}$ \\
\hline $25 \%$ & -0.219 & $\begin{array}{l}-0.229 \\
(-0.227)\end{array}$ & $\begin{array}{c}-0.235 \\
(-0.230)\end{array}$ & $\begin{array}{l}-0.246 \\
(-0.263)\end{array}$ & $\begin{array}{l}-0.28 \\
(-0.313)\end{array}$ & $\begin{array}{l}-0.345 \\
(-0.386)\end{array}$ & $\begin{array}{l}-0.376 \\
(-0.493)\end{array}$ \\
\hline
\end{tabular}

aTop value is the simultaneous scenario, bottom value is the two separate scenario effects added together. (Bold values indicate scenarios when the simultaneous scenario gives extra peak stage reduction than the two separate scenarios added together.)

downstream lower than what is expected by each individual change combined. However, for changes in magnitude greater than $2 \%$ only small time delays $(\leq 0.50 \mathrm{~h})$ produce more than the expected amount of peak stage reduction downstream.

Finally, the more physically realistic scenario of hydrograph attenuation, where the flood peak is both delayed and reduced in magnitude, with the hydrograph shape being altered, is considered. The impact of these scenarios on downstream peak stage is shown in Figure 9: the effect of attenuation of the downstream flood peak of the Upper Eden is greater than the same amount of attenuation of the Eamont, although the differences between the impact of each tributary are minor. As the amount of attenuation increases, the amount of peak stage reduction downstream increases. Furthermore, as the amount of attenuation increases, the effect of the Upper Eden diverges from the effect of the Eamont. This suggests that the Upper Eden is more effective at reducing downstream peak stage. However, while the gradient of the Eamont line is reasonably constant, the Upper Eden becomes less effective for a change factor lower than 0.85 . An attenuation factor of 0.891 is required for the Eamont flow to be reduced to bankfull height, even accounting for the error associated with the iSIS model. The attenuation factor is lower for the Eden, with a value of 0.873 .

\section{Discussion}

The above results suggest that tributary flow magnitudes exert a considerable impact upon downstream flow magnitude. But, they also suggest that the interaction of different subwatersheds in determining the magnitude of downstream floods has been demonstrated both in terms of synchronicity and sequencing. If tributary peak flows are closer in time to the peak discharge on the main river then the flood wave traveling downstream in the main river is larger. Furthermore, if the order in which tributary peak flows occur changes, how these interact with each other and the main river has important implications for downstream flood risk.

Hydrodynamic dispersion explains the propagation of disturbances to disperse longitudinally as the flood wave travels downstream [Lighthill and Whitham, 1955; Rinaldo et al., 1991]. Hydrodynamic dispersion is illustrated in this analysis by the celerity of the flood wave being considerably lower during the 2005 event as compared to the average flood in the Eden. The celerity in different reaches and tributaries of the main river was also different. This follows Saco and Kumar's [2002] concept of kinematic dispersion. This suggests that peak stage reaches bankfull in some reaches/tributaries and not others. Geomorphological dispersion accounts for the river network structure in the propagation of the flood wave downstream [Rinaldo et al., 1991]. The importance of geomorphological dispersion is demonstrated by changing the flows from one individual subwatershed, while the other tributaries flows are kept the same, and which results in differences in the downstream peak flow magnitude. The fact that some tributaries have more/less of an effect upon the downstream discharge shows that the network structure is important. White et al. [2004] found that as watershed size increases, network structure plays an increasingly important role in determining the watershed-scale response, compared to channel hydraulics. This means that in large watersheds, where runoff in the watershed is generated is critical in explaining downstream flood risk, as geomorphological dispersion overwhelms other processes operating at smaller scales. This work has found that geomorphic, 
kinematic, and hydrodynamic dispersion are important at all spatial scales, with the downstream hydrograph being primarily dependent upon geomorphic dispersion with specific reaches being subjected to different levels of kinematic and hydrodynamic dispersion. It is therefore the drainage network structure, in combination with more localized factors of flood wave celerity and attenuation, which control the watershed-scale response.

In this analysis, we have taken a single downstream point: a large urban centre. The watershed studied is unusual in that Carlisle is the only major city in the Eden watershed and it is almost at its most downstream location. From a flood risk management perspective, this justifies a singular focus upon one location. However, it is worth speculating as to what would be the effect in a similar watershed with a higher population density and perhaps more large urban centres. Here, it is possible that the spatial scale of the watershed that is relevant to a specific urban area changes depending upon which urban area is the focus, such that timing effects that matter at one spatial scale may cause opposing effects at other spatial scales. For instance, desynchronizing two tributaries may benefit the reach immediately downstream. But if this causes one of the two tributaries to become more synchronous with a third tributary, further downstream, a reduction in flood risk for one river reach may well translate into an increase for a second river reach. This is the sense in which the effects of changing the timing of tributary response can only be judged relative to those downstream locations thought to be of importance for flood risk reduction. Even if the absolute benefits of a tributary timing change can be shown, and this geomorphological effect is dominant over variability in hydrodynamic effects, this absolute benefit may not hold for all scales of consideration. The complexity of watershed-scale flood risk management comes from the problem of multiple areas of focus and concern, and how one measure in one location may benefit one urban area downstream but enhance flood risk in another.

In addition, due to temporal variation in how tributaries respond to different kinds of precipitation events, modification of the biophysical properties of watersheds is likely to be fundamentally different, as a flood risk reducing solution, to more traditional engineering solution. The same biophysical properties in one area will have different effects than in another area, depending where in the catchment they are relative to the drainage network and the downstream urban centre. These effects will be specific to different storm events, depending on how the landscape interacts with the precipitation [Pattison and Lane, 2012b]. Biophysical landscape properties can cause flow attenuation through changing the water balance, changing the timing of runoff delivery or through storage. How the biophysical properties of one area interacts with all the other areas within the catchment is what determines the cumulative effect downstream. While this study demonstrates the significant role played by attenuation in controlling downstream flood magnitude, what is less clear and needs further attention is the impact of changing the biophysical properties on the magnitude and timing of runoff, and hence attenuation. An uncertainty over the applicability of these results comes from the uncertainty over what proportion of flow magnitude reduction can be achieved through land management changes. Can this be as high as 25\%? A recent study by Wheater et al. [2008] suggests yes, with shelterbelts and full woodland cover resulting in a $29 \%$ and $50 \%$ reduction in peak flows in the Pontbren catchment, and 5\% and 36\% in the Eden catchment for the January 2005 flood event used in this paper. The second question is how much can upstream land management slow the flow? Far less research has been done on this aspect and therefore the answer is highly uncertain. Odoni and Lane [2011] found that in channel woody debris could result in up to $3 \mathrm{~h}$ delay. However, the study by Acreman et al. [2003] found that channel restoration could delay flood peaks by up to $17 \mathrm{~h}$.

\section{Conclusion}

This paper provides evidence for the important role of the drainage network structure in controlling large floods. The case study of the River Eden in the English Lake District, and the extreme January 2005 flood event, is used to demonstrate this principle. Numerical experiments were carried out using a 1-D hydraulic model, iSIS, whereby the sensitivity of downstream flood magnitude to each tributaries hydrograph was assessed. Scenarios included changing single tributary flow magnitudes and timing, as well as for multiple tributaries simultaneously. Furthermore, this provides evidence for how localized changes in watershed biophysical properties can result in very different downstream impacts depending on where they originate in the wider watershed. The dominant processes differ between scales, making it unlikely that relationships 


\section{QAGU Water Resources Research}

observed at one scale (e.g., the field) are the same at a larger spatial scale (e.g., the watershed). At the watershed scale, the role of tributary relative timing and synchronization is important in determining the magnitude of the flood peak downstream. For the single flood event considered here, it was shown that with different kinds of subwatershed response it was possible to reduce the magnitude and duration of out-ofbank flows, almost eliminating them in some scenarios. But, this conclusion also reveals a problem: even if the changes in subwatershed response can be delivered, the desired subwatershed response is likely to vary with the space-time distribution of extreme rainfall events.

\section{Acknowledgments}

This research was funded by Environment Agency and United Utilities as part of the EU Interreg IVB project ALFA (http://www.alfa-project. eu); acknowledges additional support came from Durham University and the Eden Rivers Trust. Data from the analysis included in this paper can be obtained from IP. We thank the anonymous reviewers and the Editors for critical but constructive comments on earlier drafts of this manuscript.

\section{References}

Acreman, M. C., R. Riddington, and D. J. Booker (2003), Hydrological impacts of floodplain restoration: A case study of the River Cherwell, UK, Hydrol. Earth Syst. Sci., 7(1), 75-85.

Archer, D. R., F. Leesch, and K. Harwood (2007a), Assessment of severity of the extreme River Tyne flood in January 2005 using gauged and historical information, Hydrol. Sci. J., 52(5), 992-1003.

Archer, D. R., F. Leesch, and K. Harwood (2007b), Learning from the extreme River Tyne flood in January 2005, Water Environ. J., 21, 133141.

Atkins (2005), River Eden Hydraulic Model Amendments 1999-2005 Carlisle and Eden Strategy, Atkins Consultants report.

Blöschl, G., S. Ardoin-Bardin, M. Bonnell, M. Dorninger, D. Goodrich, D. Gutknecht, D. Matamoros, B. Merz, P. Shand, and J. Szolgay (2007), At what scales do climate variability and land cover change impact on flooding and low flows?, Hydrol. Processes, 21, 1241-1247.

Cudennec, C., F. Gogien, J. Bourges, J. Duchesne, R. Kallel (2002), Relative roles of geomorphology and water input distribution in an extreme flood structure, IAHS Publication no. 271, The Extremes of Extremes: Extraordinary Floods, 187-192.

Cunderlik, J. M., and T. B. M. J. Ouarda (2009), Trends in the timing and magnitude of floods in Canada, J. Hydrol., 375, 471-480.

Delgado, J. M., H. Apel, and B. Merz (2010), Flood trends and variability in the Mekong river, Hydrol. Earth Syst. Sci., 14, 407-418.

Douglas, E. M., R. M. Vogel, and C. N. Kroll (2000), Trends in floods and low flows in the United States: Impact of spatial correlation, J. Hydrol., 240, 90-105.

Environment Agency (2006), Factual report on the meteorology, hydrology, and impacts of the January 2005 flooding in Cumbria, Cumbria floods technical report, pp. 167.

Environment Agency (2008), River Eden, Cumbria, Catchment Flood Management Plan.

Hannaford, J., and T. J. Marsh (2007), High flow and flood trends in a network of undisturbed catchments in the UK, Int. J. Climatol., 28(10), $1325-1338$.

Huntington, T. G. (2006), Evidence for intensification of the global water cycle: Review and synthesis, J. Hydrol., 319, 83-95.

JBA Consulting (2007), Ripon Land Management Project, final report, rep. SLD2332, pp. 97.

Knight, D. W., and K. Shiono (1996), River channel and floodplain hydraulics, in Floodplain Processes, edited by M. G. Anderson, D. E. Walling, and P. D. Bates, Wiley, Chichester, U. K.

Lane, S. N. (2003), More floods, less rain? Changing hydrology in a Yorkshire context, in Global Warming in a Yorkshire Perspective, edited by M. Atherden, Place Research Centre, College of Ripon \& York St. John, York, U. K.

Lane, S. N., and D. G. Milledge (2012), Impacts of upland open drains upon runoff generation: A numerical assessment of catchment scale impacts, Hydrol. Processes, 27, 1701-1726, doi:10.1002/hyp.9285.

Lane, S. N., J. Morris, P. E. O'Connell, and P. F. Quinn (2007), Managing the rural landscape, in Future Flooding and Coastal Erosion Risks, edited by C. R. Thorne, E. P. Evans, and E. C. Penning-Rowsell, pp. 297-319, Thomas Telford, London.

Lighthill, M. J., and G. B. Whitham (1955), On kinematic waves. I. Flood movement in long rivers, Proc. R. Soc. London, Ser. A, 229, 281-316. Maltby, E., and M. C. Acreman (2011), Ecosystem services of wetlands: Pathfinder for a new paradigm, Hydrol. Sci. J., 56(8), 1341-1359.

Odoni, N. A., and S. N. Lane (2010), Assessment of the impact of upstream land management measures on flood flows in Pickering Beck using overflow, in Project RMP55455: Slowing the flow at Pickering, Appendix 12.2, Department for Environment, Food and Rural Affairs, London, U. K.

Pattison, I., and S. N. Lane (2012a), The relationship between Lamb weather types and long-term changes in flood frequency, River Eden, UK, Int. J. Climatol., 32(13), 1971-1989.

Pattison, l., and S. N. Lane (2012b), The link between land-use management and fluvial flood risk: A chaotic conception?, Prog. Phys. Geogr., 36(1), 72-92.

Petrow, T., and B. Merz (2009), Trends in flood magnitude, frequency and seasonality in Germany in the period 1951-2002, J. Hydrol., 371, 129-141.

Quevauviller, P. H. (2011), Adapting to climate change: Reducing water-related risks in Europe - EU policy and research considerations, Environ. Sci. Policy, 14(7), 722-729.

Rinaldo, A., A. Marani, and R. Rigon (1991), Geomorphological dispersion, Water Resour. Res., 27(4), 513-525.

Robson, A. J. (2002), Evidence for trends in UK flooding, Philos. Trans. R. Soc. London A, 360, 1327-1343.

Rodriguez-Iturbe, I., and J. Valdes (1979), The geomorphologic structure of hydrologic response, Water Resour. Res., 15(6), 1409-1420.

Saco, P. M., and P. Kumar (2002), Kinematic dispersion in stream networks, 1. Coupling hydraulic and network geometry, Water Resour. Res., 38(11), 1244, doi:10.1029/2001WR000695.

Singer, M. B., and T. Dunne (2004), An empirical-stochastic, event based program for simulating inflow from a tributary network: Framework and application to the Sacramento River basin, California, Water Resour. Res., 40, W07506, doi:10.1029/2003WR002725.

Snell, J. D., and M. Sivapalan (1994), On geomorphological dispersion in natural catchments and the geomorphological unit hydrograph, Water Resour. Res., 30(7), 2311-2323.

Thomas, H., and T. R. Nisbet (2007), An assessment of the impact of floodplain woodland on flood flows, Water Environ. J., 21, 114-126. Wheater, H., B. Reynolds, N. McIntyre, M. Marshall, B. Jackson, Z. Frogbrook, I. Solloway, O. Francis, and J. Chell (2008), Impacts of upland land management on flood risk: Multi-scale modelling methodology and results from the Pontbren experiment, FRMRC Res. Rep. 16.

White, A. B., P. Kumar, P. M. Saco, B. L. Rhoads, and B. C. Yen (2004), Hydrodynamic and geomorphic dispersion: Scale effects in the Illinois River Basin, J. Hydrol., 288, 237-257.

Williams, G. P. (1978), Bankfull discharge of Rivers, Water Resour. Res., 14(6), 1141-1154. 